\title{
Climate change and biodiversity; impacts, vulnerability and mitigation in Indian perspective : A review
}

\section{K. Soni and Farid Ansari*}

Central Pollution Control Board (Zonal Office), PICUP Bhawan, Vibhuti Khand, Gomti Nagar, Lucknow- 226010 (U.P.), INDIA

*Corresponding author. E-mail: checkfarid@gmail.com

Received: February 16, 2016; Revised received: December 2, 2016; Accepted: February 27, 2017

Abstract: As per the nature of law, changes are bound to be happening in the system if any component of the system gets altered by any means. Change of climate and subsequently loss of biodiversity threatens the existence of human being. The loss of biodiversity, which has been happening worldwide, poses a serious threat to the anthropological system. An investigation of the current trend and future scenario shows that this loss is likely to continue in the foreseeable times. India has a huge variety of biodiversity and in the last few decades, its biodiversity has come under threat from climate change which accelerated by the anthropogenic activities of various sources of pollution. The review shows that climate change is a serious environmental challenge that undermines the determination for sustainable development. Climate change has become the most crucial environmental concern of the decade. Much attention is rightly focused on reducing carbon emissions and greenhouse gases from industrial, energy and transport sector through reduction in fuel consumption and use of renewable/green energy. However, as countries are looking for mitigation and adaptation processes, protection of natural habitats is a key factor of climate change strategies. Strengthened support for protected areas and more sustainable resource management can contribute to strategies as well as for protection of the biological resources and ecosystem. Climate change is developing as one of the greatest threats to biodiversity, increasing pressures on genetic resources, species and populations. Biodiversity conservation and sustainable development are the possible ways to curtail the impact of climate change. Although, adequate efforts have been made worldwide to tackle the environmental challenges, the adverse effects of climate change are still accelerating and the rate of loss of biodiversity is continuing globally.

Keywords: Biodiversity, Climate change, National and International conventions, Sustainable development

\section{INTRODUCTION}

The existence of human population is supported by various factors such as biodiversity, ecosystems, goods and services system provides. The factors which support the human population to flourish luxuriantly are facing rapid exceptional loss. Ecosystem is one of them, which is facing steep injury over the past few decades and posed new challenges for human survival, which need urgent attention. As reported by the Ministry of Environment, Forest and Climate Change (MoEFCC, 2014), India, a megadiverse country is contributing 7 to $8 \%$ of all recorded species, including45000 plants species and91000 animals species in the world, while India have only $2.4 \%$ of the world's land area. It is situated at the tri junction of the Afrotropical, Indo-Malayan and Palearctic realms, all of which support rich biodiversity (MoEFCC, 2014). Being one of the 17 identified megadiverse countries; India has 10 biogeographic zones and is home to $8.58 \%$ of the mammalian species known so far, with the corresponding figures for avian species being $13.66 \%$, for fishes $11.72 \%$, for amphibians $4.66 \%$, for reptiles $7.91 \%$, and for plants $11.80 \%$. Himalaya, Indo-
Burma, the Western Ghats-Sri Lanka and Sundaland are four out of 34 globally identified biodiversity hotspots are representing India (MoEFCC, 2014). Biogeographic classification for conservation development has been developed and has also mapped as biodiversity rich areas across the country.

A significant measure has been taken for inventorization of vast and diverse biological heritage. Researchers have carried out numerous studies on aquatic ecosystems, mycological work related to classification and floristic studies on abundant groups of fungi. Huge number of lichen species, which are nature's most remarkable alliances with at least 2300 species belonging to genera 305 and families 74 having been reported in country. Marine floral biodiversity of India having over 200 diatom species, 90 dinoflagellates, 844 marine algae and 39 mangrove species is remarkable (MoEFCC, 2014). Significant endemism across different plant groups in India noticed. Around 4045 species of lowering plant endemic to India are dispersed amongst 141 genera belonging to 47 families. In terms of endemism of vertebrate groups, MoEFCC reported that India's global ranking is $10^{\text {th }}$ in 
birds (69 species), $5^{\text {th }}$ in reptiles (156 species) and seventh in amphibians (110 species) (MoEFCC, 2014). Based on the origin of cultivated plants, India has 15 agro-climatic zones and has been considered to be the primary center of origin of rice. Total 811 cultivated plants and 902 of their wild relatives have been documented. Vast and rich repository of farm animals, represented by a broad spectrum of native breeds of 34 cattle, 12 buffaloes, 21 goat, 39 sheep and 15 chicken have been reported by MoEFCC in India. Abundant biodiversity of the traditional agriculture and practices in different parts of India supported food security of hundreds of millions of people across the country. The rich livestock sector plays a significant role in the Indian economy and is considered an important sub sector of Indian agriculture.

The area of Indian forests have covered over 692,027 $\mathrm{km}^{2}$, cover $21.05 \%$ of the topographical area of the India, whereas forest cover has either remained static or has reduced in most of the developing countries. India has added around three million hectares of forest and tree cover over the last decade. The MoEFCC reported that the total tree cover in India is estimated to be 9.08 million hectares, accounting for about $3 \%$ of the total topographical area of the India. Network of 54 National Parks covering 21,003 km and 373 Sanctuaries covering 2288,649 km, giving a combined coverage of $1,09,652 \mathrm{~km}$. i.e. $3.34 \%$ of the country's geographical area in $198 \mathrm{~km}$. The network has grown gradually, and up to 2014 total of 690 Protected Areas which comprises National Parks 102, Wildlife Sanctuaries 527, Conservation Reserves 572 and Community Reserves 4, covering $5.07 \%$ of the country's geographical area. Apart from this, country has 23 marine Protected Areas in peninsular India and 106 in the islands, in spite of facing a variety of threats, ranging from land use changes in natural habitats to overexploitation of natural resources, and climate change.

Threats to biodiversity: Indian biodiversity faces a variety of direct and indirect effects and challenges. National Forest Commission reported that the amount of these effects and challenges is very high, with as many as a third of all endemic species facing the threat of extinction (NFC, 2006). The key threats confronting India's biological resources are similar to the ones faced globally, viz., habitat loss, fragmentation and degradation; unsustainable use and overexploitation; pollution; invasive alien species; climate change and desertification.

The demands of a growing human population for food, medicine, fiber, fodder, shelter and fuel, along with the need for economic development, are putting and exponentially growing pressure on biodiversity and ecosystems across the country. Land use change, especially the expansion and intensification of agriculture, is creating pressure on habitats in some regions of the country through loss and fragmentation of forests, grasslands, scrublands, wetlands and other habitats. Agricultural escalation leading to loss of habitat heterogeneity, effects of agrochemicals on wild species, pollution and eutrophication due to agricultural runoff also threaten both species and the habitats they occur in.

Climate change and biodiversity: Climate change has been emphasised as serious threats to biodiversity which are likely to be adversative for biodiversity. Variation in precipitation and temperature are two important aspects of climate variability that are likely to have a direct and significant effect on India's biodiversity. Thuiller (2007) has stated that each $1^{0} \mathrm{C}$ rise in temperature will lead to shifting the zone of occurrence of several specialist species by 160 meter vertically and $160 \mathrm{~km}$ horizontally. Although the specific impact of climate change on India's natural resources area wise is yet to be studied. Sukumar (1995) reported that endemic mammals like the Nilgiri Thar face an increased risk of extinction.

Study of Intergovernmental Panel on Climatic Change (IPCC), a United Nations Scientific Consortium, reported that impact of climate change on biodiversity are expected to increase in magnitude and prevalence as $\mathrm{CO}_{2}$ levels and temperatures continue to rise and in extreme conditions, i.e., heat and storms, increase in frequency and intensity (IPCC, 2007).In mitigating and

Table 1. Overview of physical changes associated with climate change and examples of the potential ecological consequences associated with these changes.

\begin{tabular}{ll}
\hline Observed physical change & Examples of potential impacts on biodiversity \\
\hline Increased ambient temperature & $\begin{array}{l}\text { Species and population range shifts and/or changes in phenology leading to } \\
\text { alteration or loss of biotic interactions }\end{array}$ \\
Changes in annual and seasonal precipitation & $\begin{array}{l}\text { Changes in community composition } \\
\text { Mortality resulting from flooding after storms or drought events; damage or } \\
\text { mortality resulting from deep freezes or heat waves }\end{array}$ \\
Increased frequency of extreme events & $\begin{array}{l}\text { Reduced stream flow affecting population persistence and community compo- } \\
\text { sition }\end{array}$ \\
Changes to hydrologic regimes & Changes in community composition \\
Changes to fire regimes & Change in water chemistry affecting calcification rates of marine organisms \\
Ocean acidification & Habitat loss and fragmentation affecting population persistence \\
Sea level rise & Reduced productivity of pelagic ecosystems \\
Increases in ocean stratification & Changes in productivity of coastal ecosystems and fisheries \\
Changes in coastal upwelling &
\end{tabular}


Table 2. Time line detailing the international response to climate change.

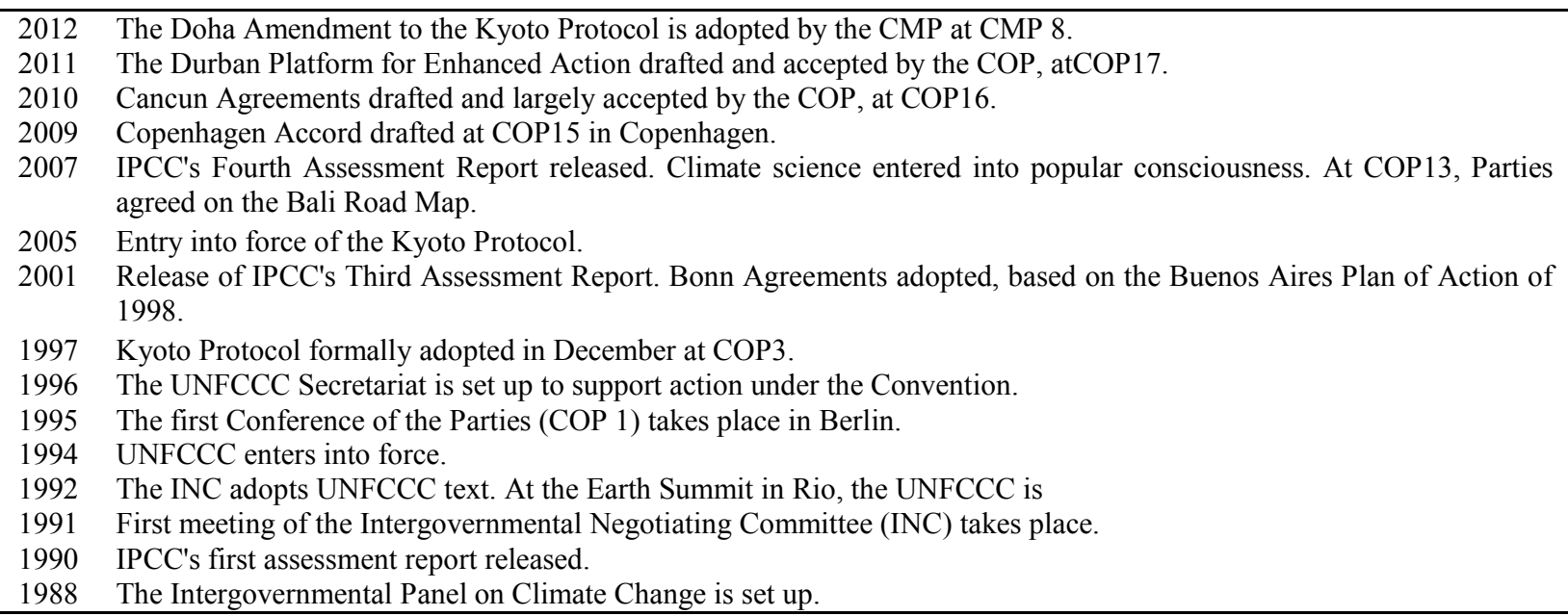

adapting the impacts of climate change, biodiversity plays a key role. Entire ecosystems such as forests and peat lands sequester carbon in their vegetation and soil thus supporting climate-regulating functions worldwide (Amend and EiIng, 2010; Carlson et al., 2010). It has been observed that emissions of greenhouse gases are threatening the biodiversity globally. In 2007, a prediction was made by the IPCC, that by the end of the $21^{\text {st }}$ century, global surface temperature may rise by 1.8 to $4^{0} \mathrm{C}$ and concluded that an increase of 1.5 to $2.5^{\circ} \mathrm{C}$ would threaten 20 to $30 \%$ of plant and animal species of the world with extinction. Bates et al., (2008) reported that climate change may adversely impact more than 5,000 plant species due to the loss of their suitable habitats.

Gitay et al. (2002) stated that the global mean surface temperature has increased by $0.6^{\circ} \mathrm{C}$ over the last 100 years. The IPCC and Anon (2007) predicted an increase in global average temperature between $0.1-0.3^{0} \mathrm{C}$ per decade. IPCC (2007) also reported that the rise in $\mathrm{CO}_{2}$ concentration from 280 parts per million (ppm) in 1750 to $379 \mathrm{ppm}$ in 2005 to approximately $395 \mathrm{ppm}$ at present, signifying the main role in increasing the global atmospheric $\mathrm{CO}_{2}$ levels. The IPCC reports state that human activities have tremendously influenced the global water cycle by impacting the global carbon cycle (NASA, 2010). India has extreme degree of sensitivity towards the climate change, due to excessive population pressure and a consequential strain on natural resources.

In Socio economic development the people, Climate plays a critical role in the lives and livelihoods. Climate has shown warming of $0.89^{\circ} \mathrm{C}(0.69$ to $1.08^{0} \mathrm{C}$ ) during the period $1901-2012$ which is mainly attributed to anthropogenic activities (IPCC, 2013). IMD (2012) stated that increasing temperature trends of the order of $0.60{ }^{0} \mathrm{C}$ during last 112 years. Goswami et al. (2006) stated that increase in heavy rainfall events and decrease in low and medium rain fall events over India have been observed.
Frequent occurring of extreme weather conditions such as hurricanes and climate change will have impact on coastal development, water supply, energy, agriculture, and health, among other sectors. Parmesan (2006) and Bellard et al. (2012) reported that the climate change causes widespread impacts across multiple scales of biodiversity including genes, species, communities, and ecosystems.

Climate change promotes changes of the abiotic conditions that influence biological systems and processes as indicated in table 1. Biological responses of climate change depend on several factors including the rate, magnitude, character of the change, ecological sensitivity and adaptive capacity to environmental change. It is also reported that combination of these factors affecting all levels of biodiversity (Walther, 2010).

IPCC has predicted that the resilience of many ecosystems will be threatened by an unique combination of climate change, associated disturbances such as drought, flooding, wildfire etc., other global change drivers such as land use change, pollution, fragmentation of natural systems, and overexploitation of resources (IPCC, 2007; CBD, 2009). Campbell (2009) reported that the climate change may also accelerate the damage to wetlands and fresh water ecosystems, such as lakes, marshes and rivers. Increasing temperature will cause water quality to deteriorate and have negative impacts on aquatic organisms, with the possibility of some species becoming extinct.

Vulnerability and risk to climate change: Climate change is affecting biodiversity in numerous ways and impacts are expected to increase in the century ahead; thus, evaluation of the risks and exposures of biodiversity is needed to inform decision-making and where and how to most effectively allocate scarce resources. The vulnerability of biodiversity to climate change is dependent on the character, magnitude, rate of changes experienced by a species or system (exposure), the degree to which they are, or are likely to be, affected by or responsive to those changes (sensitivity), and the 
ability to accommodate with impacts with minimal disruption (IPCC, 2007; Williams et al., 2008; Glick et al., 2011). Each of these factors is difficult to measure due to uncertainties in climate change projections in the coming decades and gaps in our knowledge of biological and ecological responses to these changes (Glick et al., 2011). The biodiversity is impacted by a range of anthropogenic stressors including land use change, non-native invasive species, exploitation, pollution and disease. In many cases, other stressors are currently (Flather et al., 1997, Wilcove et al., 1998)or are expected to be the primary drivers of biodiversity loss. Overall, it is anticipated that the impacts of climate change will become increasingly prevalent and dominant in the coming decades and interact synergistically with existing stressors to affect biodiversity's vulnerability (Brook et al., 2008; Barnosky et al., 2011; Mantyka et al., 2012). Although the net effect on biodiversity globally is expected to be markedly negative (Bellard et al., 2012).

Therefore an urgent priority is to carry out a comprehensive inventory and catalogue the status of biological diversity in the country before they are lost forever. This will enable the formulation of effective biodiversity management plans and also the ability to determine if biodiversity changes are due to environmental degradation driven by other factors or due to climate change.

Authors made efforts to consolidate information available a different corner of literature using modern information system incorporating their own opinion. The findings of this review demonstrate that climate change is having and will continue to have, widespread and varied impacts across all components of biodiversity. Author tried to describes the current and future impacts of climate change on biodiversity, key vulnerabilities, risks, and potential strategies that may be implemented to reduce risk.

Climate change is causing many species to shift their geographical ranges, distributions, and phenologies at faster rates than were previously thought; however, these rates are not uniform across species. Increasing evidence suggests that range shifts and novel climates will result in new community assemblages, new associations among species, and promote interactions that have not existed in the past. Differences in how organisms respond to climate change determine which species or populations will benefit (winners), and which will decline and possibly go extinct (losers) in response to climate change. Identifying highly vulnerable species and understanding why they are vulnerable are critical to developing climate change adaptation strategies and reducing biodiversity loss in the coming decades. As species shift in space and time in response to climate change, effective management and conservation decisions require consideration of uncertain future projections as well as historic conditions.
International approach on climate change: Climate Change is a very serious universal environmental problem. Efforts are being made locally as well as at global level to minimise the impact on environmental incorporating holistic approach. The approach which has been adopted at national and international (table 2) are discussed as under.

United nations climate change conference: In November, 2015 United Nations Climate Change Conference, COP 21 was held in Paris, France. First time in the conference, it was concluded to meet their objective i.e. a global agreement on reduction of climate change in the Paris, which was adopted with acclamation by nearly all states. According to the organizing committee, (UN Report, 2015), the expected key result was to restrict the global warming, by 2100 , compared to pre-industrial to below $2^{0} \mathrm{C}$. The goal to limit temperature increase with $2{ }^{0} \mathrm{C}$ was however supplemented in the adopted version of the Paris Agreement, (Adoption of the Paris agreement, 2015) with the statement that parties "pursue to" limit the temperature increase to $1.5{ }^{\circ} \mathrm{C}$.Sutter et al. (2015) reported that the goal of $1.5^{\circ} \mathrm{C}$ will require a zero level in emissions sometimes between 2030 and 2050. However, no comprehensive time plan or country-specific goals for emissions were stated in the final form of the Paris Agreement. A zero level would be reached during the second half of the century according to the treaty.

Intergovernmental panel on climate change (IPCC): The intergovernmental panel on climate change is a dedicated body jointly established by the World Meteorological Organisation and the United Nations Environmental Programme (UNEP) has been assigned to prepare comprehensive document on scientific assessments of various aspects of climate change. Fifth assessment report on climate change is being prepared by IPCC with the help of three working groups i.e. group-I working on climate change and will present the physical science basis; group - II working on climate change dealing with impacts, adaptation and susceptibility; and group - III working on assessment for mitigation of climate change.

The United nations' framework convention on climate change (UNFCCC): The UNFCCC came in existence on 21 March 1994. Total 195 countries that have ratified the convention are called parties for the convention. The Rio Convention was adopted by UNFCCC at the Rio Earth Summit in 1992. The prime goal of the convention was to make stable the concentrations of greenhouse gas at a level that would prevent dangerous man made interference with the climate system. The convention puts the burden on the developed countries to take leading role. The indication is that, as they are the source of most past and present greenhouse gas emissions. Industrialized countries are expected to do optimum efforts to cut down emissions 
on home ground.

The Kyoto protocol: A commitment by the parties for setting the internationally binding on emission reduction targets was made under the Kyoto Protocol which was linked to the United Nations Framework Convention on Climate Change and it was adopted in Kyoto, Japan, in December 1997and come into force in February 2005. The comprehensive rules for the implementation of the protocol were adopted at COP 7 in 2001 at Marrakesh, Morocco, and have been referred to as the "Marrakesh Accords." It was started in 2008 and ended in 2012. Under this protocol, all concerned countries must comply their targets primarily through in house measures. Although, the protocol also offers them an additional means to meet their targets by way of three markets based mechanisms i.e. International Emissions Trading, Clean Development Mechanism and Joint implementation.

The Bali road map: At $13^{\text {th }}$ conference of the parties (3rd meeting) the Bali Road Map was adopted in December 2007 in Bali. It was a set of progressive verdicts that represent the work that needs to be done under various negotiating "paths" which is necessary to get a secure climate future. This Map includes the Bali Action Plan, which plans the course for a new negotiating process designed to handle climate change. It has been divided into five main categories i.e. shared vision, mitigation, adaptation, technology and financing.

The Cancun agreements: At international level, under the UNFCCC largest collective effort was made by world for reduction of emission in a mutually accountable way in Cancun Agreements. The Cancun Agreements reached on December in Cancun, Mexico, at the 2010 United Nations climate change conference, denoted key steps forward in capturing plans to reduce greenhouse gas emissions, and to helping developing nations to protect themselves from climate impacts and build their own sustainable futures. The main objectives of Cancun Agreements include mitigation, capacity building, transparency of actions, forests, technology, adaptation and finance. Setting up the green climate fund to disburse hundred billion dollar every year by 2020 to developing countries to assist them in mitigating climate change and adapting to its impacts was also one of the objective of agreements.

The Durban agreement: The United Nations Climate Change Conference held in 2011 in Durban carried innovation on the international community's response to Climate Change. For the first time, world governments committed themselves to write a comprehensive global agreement to decrease greenhouse gas emissions, including developed and developing countries, to come into force in 2020.

The Doha climate gateway: A conference on climate change was organised by UN at Doha, Qatar in 2012 as COP18/ CMP8 to compile the achievement gain in the past three year in climate change negotiation and make road map for required ambition and action at all level. One of the decision that they agreed, to keep temperature below an agreed maximum $2^{\circ} \mathrm{C}$ rise, exceeding this may leads to serious consequences. They also agreed that to put more efforts to find the avenues to curb the emission and bring down the level before 2020. UN Secretary General Ban Ki-moon announced at Doha that UN will convene world leaders in 2014 to mobilize political will to ensure the 2015 deadline is met.

Climate change and India's actions: As per estimation approx., 1331.6 million tonnes of the carbon dioxide equivalent greenhouse gas (GHG) emissions was in 2007. The annual growth of $4.2 \%$ in emissions levels since 1994 level recorded in which India's contribution in $\mathrm{CO}_{2}$ emissions was about $4 \%$ of total global $\mathrm{CO}_{2}$ emissions and is much less if the historical concentrations are taken into account. India still conscious about the global challenge of climate change. In fulfilment of the obligations on parties to the United $\mathrm{Na}$ tions framework convention on climate change (UNFCCC), India has assumed to communicate information about the implementation of the convention, taking into account the common but differentiated responsibilities, respective capabilities, their specific regional and national development priorities, objectives and circumstances.

Indian view on International accord on climate change at Paris 2015: India is dedicated to engage actively in multifaceted negotiations under the UNFCCC Paris, 2015 in a positive, inventive and progressive manner. The main objective of the country is to institute an effective, cooperative and unbiased global planning based on climate justice and the principles of parity and common but distinguished responsibilities and respective capabilities, under the UNFCCC. India set an ambitious target to achieve $40 \%$ of its power from renewable resources by 2030 .Recently Govt. of India has launched a solar power treaty aimed at growing solar power generation in the developing world. India also set a target to upgrade $100 \mathrm{GW}$ of solar power production capacity by 2022 , a huge rise up from current capacity (TIME, 2015).

National environment policy: An essential element of India's response to climate change has been outlined in National Environment Policy, 2006. These, inter-alia, include observance to principle of common but differentiated responsibility and respective capabilities of different countries, identification of key liabilities of India to climate change, in particular impacts on forests, coastal zones, agriculture, water resource and health, assessment of the need for adaptation to climate change and inspiration to the industry to join in the Clean Development Mechanism (CDM).

Prime Minister's council on climate change: An advisory group on climate change issues which 
include: government representatives and non- government members was set up by the Prime Minister. Thy coordinate's national action plans for adaptation, assessment and mitigation of climate change. Govt. is also being advised on proactive measures that can be taken by India to deal with the challenge of climate Change. It will also expedite inter-ministerial coordination and guide policy in relevant areas.

The National action plan on climate change (NAPCC): A compilation was released on in June 2008 on current and future policies and programs to address climate mitigation and adaptation, first time by the NAPCC. The MOEFCC is coordinating the plan and implementing through the nodal Ministries in specific areas. Different national missions such as National Solar Mission, National Mission for Enhanced Energy Efficiency, National Mission on Sustainable Habitat, National Water Mission, National Mission for Sustaining the Himalayan Ecosystem, National Mission for a Green India, National Mission for Sustainable Agriculture, National Mission on Strategic Knowledge for Climate Change, have been notified under the NAPCC. They also emphases on other ongoing key initiatives, including clean energy for sustainable development \&renewable energy.

Parliamentary forum on global warming and climate change: The forum was constituted by government of India for the first time in 2008 and since then has been involving parliamentarians to interact with specialists working on global warming and climate change. A road map was communicated by the Government of India to the UNFCCC for $20-25 \%$ reduction in the emission intensity of Indian GDP by the year 2020 .

Climate change action programme (CCAP): Various other aspects of scientific initiatives planned by the MOEF \& CC as part of the Climate Change Action Programme (CCAP). These include Long Term Ecological Observatories (LTEO), National Carbonaceous Aerosols Programme (NCAP), and Studies on Climate Change for North East region (CSCCNE). The NCAP is a major activity involving multi-agency and multi-institutional study.

Indian network for climate change assessment (INCCA): INCCA is a proposed network of scientists in India and dedicated to set up to publish peerreviewed findings made on climate change in India tasked with undertaking research on the science of climate change and its impacts on different sectors of economy across various regions of India.

Twelfth five-year plan and climate change: Domestic mitigation goal of the Government of India has for reduction of emissions amount of Gross Domestic Product (GDP) by $20-25 \%$ by 2020 in comparison with 2005 level.The energy strength of India's output has shown a declining trend due to improvements in energy efficiency, autonomous technological changes and economical use of energy. At national and state level different kind of scheme aims at advancing scientific research, information and assessment of the phenomenon of climate change planned. Work on institutional and analytical capacity for research and studies in the area of climate change and supporting domestic actions to address climate change through specific programmes is also in progress. The scheme comprises of eight activities i.e. related to scientific studies on climate change, two related to institution and capacity building, three others related to domestic and international actions.

Other initiatives: India is participating at the subregional level to tackle the adverse impacts of climate change. India partnered with Bhutan, Nepal and Bangladesh for cooperation through adaptation actions in the four thematic areas of water, energy, food and biodiversity.

\section{Conclusion}

Climate change has become the most essential environmental concern of the decade. Significant consideration is required to focus on reducing carbon and greenhouse gas emissions from energy, industrial and transport sources, through reduction in quality and quantity of fuel use, implementation of improved and advance technologies, enhances public understanding about the environment they live, sensitisation on the importance of biodiversity and climate change. Promoting the appropriate and effective coordination among biodiversity and climate change programs in India by incorporating the eco-friendly environmental policy, bringing the biodiversity and climate change into national plans and programs. Developing policy, guidelines for biodiversity, climate change and reduce the vulnerability of local communities to climate change impacts and enhance the flexibility of local communities to the impacts of climate change. Public participation is necessary to integrate ecosystem conservation and rural development, because it is necessary to know the needs for they depend on a particular ecosystem. Identify the key sectors of the country vulnerable to climate change, in particular impacts on water resources, agriculture, health, coastal areas and forests. Promote research to develop methodologies for tracing changes and evaluating impacts of climate change on glaciers, river flows and biodiversity. Assess the need for adaptation to future impacts of climate change at national and local levels, and the scope for incorporating the outputs of such assessments relevant programmes, including watershed management, coastal zone planning and regulation, agricultural technologies and practices, forestry management, and health programmes. Explicitly consider vulnerability of coastal areas and their biodiversity to climate change and sea level rise in coastal management plans, as well as infrastructure planning and construction 
norms. Identify the most important gaps in knowledge that limit the national ability to develop and implement climate change adaptation policies for organisms, and ecological processes and functions. Enhance the capacity of climate modelling in the country substantially to get clear idea on the impacts of climate change on biodiversity at national and local levels. The authors endeavour's to summarize the important vulnerable issues associated with the present and potential future responses due to climate change and highlighted those areas where further research is required.

\section{REFERENCES}

Amend, T. and Eilng, S. (2010). Sustainability has many faces. Nature and Mankind facing climate change, Deutsche Gesellschaftfür Technische Zusammenarbeit (GTZ) Gmbh

Bates, B. C., Kundzewicz, Z. W., Wu, S. and Palutikof, J. P. (2008). Climate Change and Water, Technical Paper of the Intergovernmental Panel on Climate Change, IPCC Secretariat, Geneva

Barnosky, A. D., Matzke, N., Tomiya, S., Wogan, G. O., Swartz, B., Quental, T. B., Marshall, C., McGuire, J. L., Lindsey, E. L. and Maguire, K. C. (2011). Has the Earth's sixth mass extinction already arrived? Nature. 471:51-57

Bellard, C., Bertelsmeier, C., Leadley, P., Thuiller, W. and Courchamp, F. (2012). Impacts of climate change on the future of biodiversity. Ecology Letters 15: 365-377

Brook, B. W., Sodhi, N. S., and Bradshaw, C. J. A.(2008). Synergies among extinction drivers under global change. Trends in Ecology \& Evolution. 23:453-460

Campbell, A., Kapos, V., Scharlemann, J. P. W., Bubb, P., Chenery, A., Coad, L., Dickson, Doswald, N., Khan, M. S. I., Kershaw, F. and Rashid, M. (2009). Review of literature on the Links between Biodiversity and Climate Change: Impacts, Adaptation and Mitigation. Secretariat of the Convention on Biological Diversity, Montreal. Technical Series No. 42

Carlson, M., Chen, J., Elgie, S., Henschel, C., Montenegro, A., Roulet, N., Scott, N., Tarnocai, C. and Wells, J. (2010). Maintaining the role of Canada's forests and peatlands in climate regulation. The Forestry Chronicle, $86,(4)$

CBD (2009). The Convention on Biological Diversity: Year in Review 2009 edited, researched and compiled by Johan Hedlund, CBD Secretariat

Flather, C. H., Wilson, K. R., Dean, D. J. and Mc. Comb, W. C. (1997). Identifying gaps in conservation networks: of indicators and uncertainty in geographic-based analyses. Ecological Applications. 7: 531-542

Gitay, H., Suarez, A., Watson, R.T. and Dokken, D.J. (2002). Intergovernmental Panel on Climate Change, Technical paper $V$

Goswami, B.N., Venugopal, V., Sengupta, D., Madhusoodanan, M.S. and Xavier, P. K. (2006). Increasing trend of Extreme Rain Events over India in a
Warming Environment. Science. 314, 5804, 1442-1445. Glick, P., Stein, B.A. and Edelson, N. (2011).Scanning the conservation horizon: a guide to climate change vulnerability assessment. Washington, DC: National Wildlife Federation. Available at: www.nwf.org/ vulnerabilityguide

IPCC (2007). An assessment of Intergovernmental Panel on climate change. Climate change synthesis report, Cambridge University Press, Cambridge, U.K. p-73

IPCC (2013). Climate Change, The Physical Science Basis. Cambridge University Press, U.K.

IMD (2012). Annual Climate Summary. National Climate Centre, Pune

MoEFCC (2014). India's fifth national report to the convention on biological diversity 2014, Ministry of Environment, Forests and Climate Change, New Delhi, India

Mantyka, Pringle, C. S., Martin, T. G. and Rhodes, J. R. (2012). Interactions between climate and habitat loss effects on biodiversity: a systematic review and metaanalysis. Global Change Biology 18:1239-1252

National Forest Commission (2006). Report of the National Forest Commission. New Delhi: Ministry of Environment and Forests

NASA (2010). Global warming/ www.earthobservatory. nasa.gov

Parmesan, C. (2006). Ecological and evolutionary responses to recent climate change. Ecology Evolution.(37): 637-669

Sutter, John D. and Berlinger, J. (2015). Final draft of climate deal formally accepted in Paris. CNN. Cable News Network, Turner Broadcasting System, Inc. Retrieved 12 December 2015

Sukumar, R., Suresh, H.S. and Ramesh, R. (1995). Climate change and its impact on tropical montane ecosystems in southern India. Journal of Biogeography, 22:533536

Thuiller W. (2007). Climate change and the ecologist. $\mathrm{Na}$ ture, (2): 550-552

Time (2015) http://time.com/4144843/india-paris-climatechange/

UNFCCC (2015). 19th Session of the Conference of the Parties to the UNFCCC. International Institute for Sustainable Development

UNFCCC (2015). Adoption of the Paris agreement, Proposal by the President, Draft decision CP.21. Archived from the original on 2015-12-12

UN Report (2015). New UN Report Synthesizes National Climate Plans from 146 Countries, UNFCCC

Walther, G. R. (2010). Community and ecosystem responses to recent climate change. Philosophical Transactions of the Royal Society B-Biological Sciences 365:2019-2024

Williams, S. E., Shoo, L.P., Isaac, J. L., Hoffmann, A.A. and Langham, G. (2008). Towards an integrated framework for assessing the vulnerability of species to climate change.PLoS Biology (6): 2621-2626

Wilcove, D. S., Rothstein, D., Bubow, J., Phillips, A. and Losos, E. (1998). Quantifying threats to imperilled species in the United States. BioScience, 48(8), 607-615 